\title{
Inclusive Education for Students with Disability
}

\author{
Ikhfi Imaniah ${ }^{1 *}$, Nurul Fitria ${ }^{2}$ \\ ${ }^{1}$ English Education Department, Faculty of Teachers Training and Education, Muhammadiyah University of Tangerang, Indonesia \\ ${ }^{2}$ Young Learners Education Department, Faculty of Teachers Training and Education, Muhammadiyah University of Tangerang, \\ Indonesia
}

\begin{abstract}
This paper identifies and discusses major issues and trends in special education in Indonesia, including implications of trends for the future developments. Trends are discussed for the following areas: (1) inclusion and integration, issues will remain unresolved in the near future; (2) early childhood and postsecondary education with disability students, special education will be viewed as lifespan schooling; (3) transitions and life skills, these will receive greater emphasis; and (4) consultation and collaboration, more emphasis but problems remain. Moreover, the participant of the study in this paper was an autism student of twelve years old who lived at Maguwoharjo, Yogyakarta. This study was qualitative with case study as an approach of the research. The researchers conclude the autism that has good academic, communication and emotional skill are able to go to integrated school accompanied by guidance teacher. But in practice, inclusive education in Indonesia is inseparable from stakeholders ranging from government and institutions such as schools, educators, school environment, community and parents to support the goal of inclusive education itself. Adequate infrastructure also needs to be given to the school that organizes inclusive education for an efficient and effective students understanding learning-oriented of inclusive education. In short, every child has the same opportunity in education, yet for special education which is aimed at student with special educational needs.
\end{abstract}

Keywords: inclusive education, early childhood, integrated school.

\subsection{Introduction}

In recent years, the concept and practice of inclusive education have gained importance. Internationally, the term is increasingly understood more broadly as a reform that supports and welcomes diversity amongst all learners ${ }^{[1]}$. Inclusive education can be seen as a process of strengthening the capacity of an education system to reach out to all learners. It is, therefore, an overall principle that should guide all educational policies and practices, starting from the belief that education is a fundamental human right and the foundation for a more just society. Education takes place in many contexts, both formal and non-formal, and within families and the wider community. Consequently, inclusive education is not a marginal issue but is central to the achievement of high quality education for all learners and the development of more inclusive societies ${ }^{[2]}$. Inclusive education is essential to achieve social equity and is a constituent element of lifelong learning. In short, inclusive education is a process that involves the transformation of schools and other centres of learning to cater for all children - including boys and girls, students from ethnic and linguistic minorities, rural populations, those with disabilities and difficulties in learning and to provide learning opportunities for all youth and adults as well. Its aim is to eliminate exclusion that is a consequence of negative attitudes and a lack of response to diversity in race, economic status, social class, ethnicity, language, religion, gender, sexual orientation and ability.

Most countries adopt the principles of Education for All (EFA) in their policies and laws, but in practice, education is for "almost all" or for "most people" and the people excluded are precisely those who need it most, in order to compensate their disadvantaged social and educational situation. According to the EFA Global Monitoring Report 2008, there are still 72 million of children in the world who have no access to primary education and 774 million of young people and adults who are illiterate, $64 \%$ of which are women.

Access to early childhood care and education, necessary to guarantee equal opportunities, is quite limited in the three first years, and children from the most disadvantaged socio-economic contexts and from rural areas hardly benefit from these services. Access to secondary education has increased by 5\%, from 2000 to 2005 , reaching $66 \%$. Nevertheless, a greater effort should be made since nowadays primary education is not enough for being included into the knowledge society and emerging from poverty.

Education quality and equality are unresolved matters even in those countries with high schooling rates. There are large disparities among and within countries as regards the access to the different educational levels and the distribution of knowledge. Only $63 \%$ of countries with available data have reached gender parity in primary education, decreasing to $37 \%$ at the secondary level. Students from economically disadvantaged sectors, rural areas or minorities are those who, due to a structural situation, show higher repetition and drop-out rates and achieve lower learning outcomes ${ }^{[3]}$.

\footnotetext{
*Iqvee.sorrow@gmail.com
} 
Moreover, segregated schools and programs exist, which are aimed at people with special educational needs, of different ethnic origin, or migrant families. Many of these students are not treated with human dignity; their culture is not respected and they are victims of physical or psychological violence.

Therefore, educational exclusion is an important phenomenon which is not restricted to those who do not attend school because of a denial of access, or because they dropped out of school due to repetition, the lack of relevance of the education, economic obstacles or the students' life circumstances. Exclusion also affects those who attend school but are segregated or discriminated against because of their ethnic origin, gender, social condition, of other individual characteristics or capacities, as well as those who cannot learn due to the low quality of the education they receive.

Based on the observation at Mugowoharjo, Yogyakarta, Indonesia; there is an eight year student who has disability which study at one of formal school at Yogjakarta. He looks normal like other students, but he is not; he is autism. He needs guide from the teacher during the learning process. So far, inclusion has been presented through a disability lens. Inclusion should, however, not be seen as an issue solely about students with disability. Many, however, now view inclusive education as being concerned with diversity more generally. According to Shaddock and colleagues (2009), inclusion implies that if participation becomes an issue for any student, whether arising from disability, gender, behaviour, poverty, culture, refugee status or any other reason, the desirable approach is not to establish special programs for the newly identified individual or group need, but to expand mainstream thinking, structures, and practices so that all students are accommodated.

\subsection{Result and Discussion}

\subsubsection{Inclusion and Integration}

Inclusive education is a process of strengthening the capacity of the education system to reach out to all learners and can thus be understood as a key strategy to achieve EFA. As an overall principle, it should guide all education policies and practices, starting from the fact that education is a basic human right and the foundation for a more just and equal society. The major impetus for inclusive education was given at the World Conference on Special Needs Education: Access and Quality, held in Salamanca, Spain, June 1994. More than 300 participants representing 92 governments and 25 international organizations considered the fundamental policy shifts required to promote the approach of inclusive education, thereby enabling schools to serve all children, particularly those with special educational needs ${ }^{[4]}$.

Although the immediate focus of the Salamanca Conference was on special needs education, its conclusion was that: Special needs education - an issue of equal concern to countries of the North and of the South - cannot advance in isolation. It has to form part of an overall educational strategy and, indeed, of new social and economic policies. It calls for major reform of the ordinary school.

An 'inclusive' education system can only be created if ordinary schools become more inclusive - in other words, if they become better at educating all children in their communities. Inclusion is thus seen as a process of addressing and responding to the diversity of needs of all children, youth and adults through increasing participation in learning, cultures and communities, and reducing and eliminating exclusion within and from education. It involves changes and modifications in content, approaches, structures and strategies, with a common vision that covers all children of the appropriate age range and a conviction that it is the responsibility of the regular system to educate all children.

The term inclusion has different interpretations in various countries. It is sometimes associated with those students living in marginalized or poor contexts, but frequently it is related to the participation of the disabled or those with special educational needs in mainstream schools. In this way inclusion is considered to be almost the same as integration, when they are in fact two different approaches with different visions and perspectives. As a consequence of this misconception, inclusive policies are regarded as a responsibility of special education, restricting the analysis of all the common forms of exclusion and discrimination that take place within education systems.

In the case of inclusion, on the contrary, the focus is on the transformation of education systems and schools so that they can cater for the diversity of students' learning needs resulting from their social and cultural background and their individual characteristics as regards learning motivations, abilities, styles and rhythm. According to this perspective, it is not the students enrolled in school that must adapt to the existing educational provision, but rather the school that should be adapted to the needs of every student, since all students are different. Corps, Ceralli, and Boisseau (2012) explain that special education system means children with disabilities receiving an education in a segregated learning environment such as a special school or centre that is often isolated from the community, from other children, or from the mainstream education schools. In many countries this type of special education system has no link to the Ministry of Education. ${ }^{[5]}$

The key element of inclusion is not individualization but the diversification of the educational provision and the personalization of common learning experiences in order to achieve the highest degree of participation of all students, taking into account their individual needs. This implies advancing towards universal design, where the teaching learning process and the curriculum consider from the very beginning the diversity of needs of all students, instead of planning on the basis of an "average" student and then carry out individualized actions to respond to the needs of specific students or groups who were not taken into consideration by an education proposal based on a logic of homogeneity instead of diversity. The response to diversity - an essential condition to achieve high quality education - is probably 
the main challenge currently faced by schools and teachers, as it involves substantive changes in the existing conceptions, attitudes, curricula, pedagogical practices, teacher training, evaluation systems and school organization.

In short, the inclusive education system takes a systematic approach to change rather than a school by school approach. ${ }^{[6]}$. Integrated education can also mean that a child with a disability is placed into a mainstream school and class, but that the school makes only minimal attempts to address any specific academic or social needs the child might have, and accordingly the child must adapt his/herself to the environment. It means classes for children with disabilities that are located in mainstream schools but in a separate classroom with other disabled learners and with a dedicated teacher. These children will often have little or no contact with their non-disabled peers. Moreover, Education system considers the measures it must take to be able to provide an appropriate education with all children learning together. Links are made with support services both special and mainstream.

\subsubsection{Early Childhood and Postsecondary Education with Disability}

The World Declaration on Education for All, adopted in Jomtien, Thailand (1990), sets out an overall vision: universalizing access to education for all children, youth and adults, and promoting equity. This means being proactive in identifying the barriers that many encounter in accessing educational opportunities and identifying the resources needed to overcome those barriers ${ }^{[7]}$.

Early childhood is a quickly expanding focus in special education. Research has supported the belief that early interventions are critical for significant improvements in exceptional individuals. There have been new laws, funding, and training established in the field to assist in supporting early childhood special education. Unfortunately, there is still a much higher demand for these services than what is currently being provided. The current emphasis in legislation has been toward expanding special education from birth to adulthood. This newer perspective is based on a view of lifespan schooling.

School-going age for children both with and without disabilities may vary from region to region and country to country. National governments have policies and laws stipulating the age limits for primary and secondary school: 1) average preschool age 3-6 years, 2) average primary school age 6-15 years, 3) average secondary school age 14-25 years. In this case, the subject of student is at twelve years old which has disability on his communication, socialization and emotional. Autism spectrum disorder (ASD) and autism are both general terms for a group of complex disorders of brain development. These disorders are characterized, in varying degrees, by difficulties in social interaction, verbal and nonverbal communication and repetitive behaviours ${ }^{[8]}$. For children with disabilities, who often begin school later than their non-disabled peers and who sometimes require additional time, the process of setting an age limit law can prevent the completion of a basic education.

Education for children with disabilities in most low and middle-income countries largely consists of segregated special schools in urban areas where infrastructure is more developed. However, evidence is beginning to show that this type of educational system is not a viable solution over the long term and invariably excludes the poorest individuals, especially in rural settings.

The past ten years have witnessed a significant global drive on the issue of access to education. Whilst much progress has been made, as demonstrated by a global decrease in the number of children out of school, there remain serious challenges in terms of quality of teaching, learning, retention and success in education. For children with disabilities, the situation is critical. Education systems and services worldwide are simply failing to meet their needs, both in terms of access and quality of education.

\subsubsection{Transition and Life Skills of Disability Students}

Most individuals learn a majority of their life skills from their families or peer groups. For individuals with special needs, these skills often become a priority for their education. Individuals who have sensory or physical disorders such as visual impairment, hearing loss, cerebral palsy or spinal bifida need to learn how to use the specialized materials and equipment that will assist them. Transition has become a growing concern of special education. The results of research on vocational and postsecondary outcomes spurred special educators to develop programs to help students with disabilities make the transition from school to work and independent living.

In line with the transition and life skills, the curriculum and teachers methods in teaching and learning process are connected to the success of students' life skills in the environment.

An inclusive curriculum addresses the child's cognitive, emotional, social and creative development. It is based on the four pillars of education for the twenty-first century - learning to know, to do, to be and to live together ${ }^{[9]}$.

It has an instrumental role to play in fostering tolerance and promoting human rights, and is a powerful tool for transcending cultural, religious, gender and other differences. An inclusive curriculum takes gender, cultural identity and language background into consideration. It involves breaking negative stereotypes not only in textbooks but also, and more importantly, in teacher's attitudes and expectations. Multilingual approaches in education, in which language is recognized as an integral part of a student's cultural identity, can act as a source of inclusion. Furthermore, mother tongue instruction in the initial years of school has a positive impact on learning outcomes.

An inclusive approach to curriculum policy has built-in flexibility and can be adjusted to different needs so that everyone benefits from a commonly accepted basic level of quality education. This ranges from varying the time that 
students devote to particular subjects, to giving teachers greater freedom to choose their working methods, and to allowing more time for guided classroom-based work.

According to the EFA Global Monitoring Report 2005, one way to move towards a relevant, balanced set of aims is to analyse the curriculum in terms of inclusion. An inclusive approach to curriculum policy recognizes that while each learner has multiple needs - even more so in situations of vulnerability and disadvantage - everyone should benefit from a commonly accepted basic level of quality education. This underlines the need for a common core curriculum that is relevant for the learner while being taught according to flexible methods ${ }^{[10]}$.

Accessible and flexible curricula, textbooks and learning materials can serve as the key to creating schools for all. Many curricula expect all students to learn the same things, at the same time and by the same means and methods. But students are different and have different abilities and needs. It is important, therefore, that the curriculum be flexible enough to provide possibilities for adjustment to individual needs and to stimulate teachers to seek solutions that can be matched with the needs, abilities and learning styles of each and every student ${ }^{[11]}$. This is particularly important in the development and practice of learning activities for youth and adults.

\subsubsection{Consultation and Collaboration}

For students that are involved with integrated programs, it is essential to implement a consultation or collaborative model of service delivery ${ }^{[12]}$. Consultant models were originally thought to be "expert models" where special education specialists would work with general educators and instruct them on how the teachers were to meet the needs of their exceptional students. This model was not appropriate in some states, where the special education teachers receive no significant additional training compared to their regular education counterparts. This model also had difficulties when experienced teachers did not want or appreciate advice about their own classrooms. Current models of consultation are more reciprocal and give the specialist either equal, or less authority than the regular education teacher. The collaboration model is a more popular method being advocated by several researchers and practitioners. Collaboration models (like consultation models) assume that the regular teacher is the primary provider of instruction and has the ultimate responsibility. The special education teacher's role is to act as a support and a resource to the regular teacher including working in the general classroom with students. The General Education Collaboration Model proposed by Simpson and Myles (1993) is composed of five essential components: 1) Flexible departmentalization, 2) Program ownership, 3) Identification and development of supportive attitudes, 4) Student assessment as a measure of program effectiveness, and 5) Classroom modifications that support mainstreaming. (p. 65)

Although collaboration models may sound ideal, there are several problems that have not yet been resolved. One problem is communication, for teachers do not always possess the skills to problem solve or work well together. Another concern is the lack of time to work with other professionals. There is also sometimes little common ground between regular and special education, with educators holding many misconceptions of the other field. Teacher education is behind in training special educators and especially regular educators to deal with these changes. The field is also at a loss as to how to adequately train teachers working in the schools. Although in-services are the current method of training working educators, there needs to be additional support, school adaptations, and classroom modifications for collaboration to be successful. The future of special education seems to be swinging toward increased collaboration. It appears that special education will be able to adapt to these changes, but it remains to be seen if the general education programs will be as receptive.

\subsection{Conclusion}

In sum up, an inclusive education system can only be created if ordinary schools become more inclusive - in other words, if they become better at educating all children in their communities. Inclusion is thus seen as a process of addressing and responding to the diversity of needs of all children, youth and adults through increasing participation in learning, cultures and communities, and reducing and eliminating exclusion within and from education. It involves changes and modifications in content, approaches, structures and strategies, with a common vision that covers all children of the appropriate age range and a conviction that it is the responsibility of the regular system to educate all children. Moreover, an inclusive curriculum addresses the child's cognitive, emotional, social and creative development. It is based on the four pillars of education for the twenty-first century - learning to know, to do, to be and to live together. But, there is common ground between regular and special education, with educators holding many misconceptions of the other field. Teacher education is behind in training special educators and especially regular educators to deal with these changes. The field is also at a loss as to how to adequately train teachers working in the schools. Although in-services are the current method of training working educators, there needs to be additional support, school adaptations, and classroom modifications for collaboration to be successful. Accessible and flexible curricula, textbooks and learning materials can serve as the key to creating schools for all. Many curricula expect all students to learn the same things, at the same time and by the same means and methods. But students are different and have different abilities and needs. It is important, therefore, that the curriculum be flexible enough to provide possibilities for adjustment to individual needs and to stimulate teachers to seek solutions that can be matched with the needs, abilities and learning styles of each and every student. But in practice, inclusive education is inseparable from 
stakeholders ranging from government and institutions such as schools, educators, school environment, community and parents to support the goal of inclusive education itself. Adequate infrastructure also needs to be given to the school that organizes inclusive education for an efficient and effective students understanding learning-oriented of inclusive education.

\section{References}

1. UNESCO. Policy Guideline on Inclusion in Education. Paris (2009)

2. S. Miles and N. Singal. The Education for All and Inclusive Education debate: Conflict, contradiction or opportunity?. International Journal of Inclusive Education. (2008)

3. UNESCO. Defining an Inclusive Education Agenda: Reflections around the 48th session of the International Conference on Education. Geneva, Switzerland. (2009)

4. UNESCO. The Salamanca Statement and Framework for Action on Special Needs Education. Paris, UNESCO/Ministry of Education, Spain. (1994)

5. H. Corps, G. Ceralli, and S. Boisseau. Inclusive Education. (2012)

6. H. Corps, G. Ceralli, and S. Boisseau. Inclusive Education. (2012)

7. UNESCO. Policy Guideline on Inclusion in Education. Paris (2009)

8. Autism Speaks Inc. Autism Speaks and Autism Speaks It's Time to Listen \& Design are trademarks owned by Autism Speaks Inc. All rights reserved. (2012)

9. J. Delors, et al. Learning: the Treasure Within. Report to UNESCO of the International Commission on Education for the Twenty-first Century. Paris, UNESCO. (1996)

10. UNESCO. EFA Global Monitoring Report 2005. The Quality Imperative. Paris, UNESCO. (2004b)

11. UIS. Investing in the Future: Financing the Expansion of Educational Opportunity in Latin America and the Caribbean, Montreal, Que.,UIS. (2004c)

12. J. Siegel. Special Education Issues, Trends, and Future Prediction. 